DOI: https://doi.org/10.47405/mjssh.v6i10.1129

\begin{tabular}{|c|c|}
\hline 4 & Malaysian Journal of Social Sciences and Humanities (MJSSH) \\
\hline $\begin{array}{l}\text { Malaysian Juoural of } \\
\text { Social ccciecces and }\end{array}$ & Volume 6, Issue 10, October 2021 \\
\hline (MJ-sSH) & e-ISSN : 2504-8562 \\
\hline & $\begin{array}{l}\text { Journal home page: } \\
\text { www.msocialsciences.com }\end{array}$ \\
\hline
\end{tabular}

\title{
Hubungan Kemahiran dan Pengetahuan Terhadap Pencapaian Kendiri Guru Bahasa Melayu di Sabah
}

\author{
Sarimawathy Jumanie ${ }^{1}$, Asmiaty Amat ${ }^{1}$, Syahrul Nizam Salam ${ }^{1}$ \\ ${ }^{1}$ Pusat Penataran Ilmu dan Bahasa (PPIB), Universiti Malaysia Sabah (UMS), Malaysia \\ Correspondence: Syahrul Nizam Salam (insantakwa@yahoo.com)
}

\begin{abstract}
Abstrak
Kajian ini bertujuan mengenal pasti hubungan pengetahuan dan kemahiran guru Bahasa Melayu terhadap pencapaian kendiri guru Bahasa Melayu di Sabah. Soal selidik sebagai instrumen kajian telah digunakan untuk mendapatkan data kuantitatif melibatkan seramai 380 guru Bahasa Melayu iaitu sebagai responden. Data kajian telah dianalisis menggunakan statistik IBM SPSS versi 22. Data yang diperoleh secara analisis inferensi menggunakan ujian statistik parametrik iaitu korelasi Pearson. Dapatan kajian daripada analisis korelasi Pearson menunjukkan terdapat hubungan yang signifikan antara tahap pengetahuan dan tahap kemahiran dengan pencapaian kendiri guru Bahasa Melayu. Implikasi daripada kajian ini, mencadangkan bahawa pencapaian kendiri guru Bahasa Melayu perlu sentiasa dipertingkatkan dan ditambah baik dari segi pengetahuan dan kemahiran dalam meningkatkan pencapaian kendiri guru Bahasa Melayu di sekolah.
\end{abstract}

Kata kunci: pengetahuan, kemahiran, pencapaian kendiri

\section{The Relationship Skills And Knowledge Towards Self-Acheivement Of Malay Language Teachers In Sabah}

\begin{abstract}
The purpose of this study is to identify the relationship of knowledge and teacher's skills on selfachievement of Malay language teachers in Sabah. The research design is descriptive using survey method. The questionnaire as a research instrument was used to obtain quantitative data involving 380 malay language teachers as selected respondents through random sampling. The data were analyzed using the IBM SPSS version 22 and the data obtained were analyzed as inferential analysis using parametric statistical test using Pearson correlation. The findings showed that the level of teachers' knowledge and skills were at high level. The pearson correlation analysis shows that there is a significant correlation between knowledge and skills level with achievement of self-concept. The implication of this study suggests that the national school should be constantly enhanced and improved in term of knowledge and skills to increasing the self-achievement of Malay language teachers at school.
\end{abstract}

Keywords: knowledge, skills, self-achievement 


\section{Pengenalan}

Konsep kendiri merupakan elemen yang penting dalam menilai pencapaian seseorang individu. Ini kerana pencapaian kendiri memerlukan pemantapan dari segi pengetahuan dan kemahiran yang baik. Dalam era globalisasi pembangunan kendiri dalam akademik sangat penting lebih-lebih lagi dalam arus perkembangan semasa yang mengutamakan pencapaian para pelajar sebagai aras perkembangan pendidikan negara sekali gus menjadi aspirasi negara untuk menjadi hub pendidikan yang mana negara menjadikan dasar pandang ke timur era moden sebagai penanda aras kemajuan pendidikan di bawah kepimpinan negara Malaysia. Perubahan secara drastik diperlukan dalam dunia pendidikan untuk mencapai kejayaan dalam strategi serta matlamat oleh Kementerian Pendidikan Malaysia (KPM) dalam meningkatkan penguasaan kendiri dalam kalangan guru menerusi agenda wawasan negara.

Dalam kajian Syahrul et al. (2018) menunjukkan pencapaian kendiri seseorang individu perlu dijadikan tunjang utama dalam setiap tindakan yang dilakukan bagi membangunkan negara bangsa berasaskan ilmu pengetahuan serta sikap dalam memperbaiki konsep kendiri seseorang individu. Dapat dilihat juga, pelbagai usaha telah dilakukan dengan kerjasama Pejabat Pendidikan Negeri Sabah (JPNS) serta Pejabat Pendidikan Daerah (PPD), termasuk program-program pembangunan kemahiran dan pengetahuan terhadap guru-guru Bahasa Melayu dalam meningkatkan pencapaian kendiri dalam kalangan guru bagi meningkatkan kemampuan serta keyakinan dalam proses pengajaran dan pembelajaran. Dapatan kajian van Rooij, Jansen, dan van de Grift (2017) menyatakan pembangunan kendiri dapat meningkatkan pencapaian seseorang individu dengan menumpukan keperluan terhadap kognitif. Justeru, guru-guru yang berhadapan dengan tahap kendiri yang rendah perlu melihat kepada sebab dan akibat perubahan tingkah laku dari awal hingga akhir menerusi dengan memfokuskan penguasaan elemen kognitif dalam diri.

\section{Sorotan Literatur}

Dalam kajian Bandura dan Adams (1977) menunjukkan kendiri seseorang adalah persepsi kemampuan yang dimiliki dalam pelbagai situasi serta keadaan yang diberi yang melibatkan aspek-aspek kognitif, afektif dan psikomotor. Dalam kajian oleh van Rooij et al. (2017) kendiri melalui persepsi minat dalam bidang akademik yang wujud dalam diri mampu membawa kejayaan dalam prestasi pembelajaran sekali gus membentuk kendiri positif ke arah kecemerlangan dalam diri seseorang. Dalam kajian yang dibuat oleh Syahrul et al. (2019) menunjukkan elemen-elemen seperti sikap, kefahaman dan kaedah pemantapan diri dapat meningkatkan penguasaan kendiri positif dalam melakukan sesuatu tindakan dan keputusan yang dibuat.

Dalam teori Kognitif Sosial, individu menurut Bandura (1991) digambarkan sebagai seseorang yang mengorganisasikan diri, proaktif, merefleksi diri dan mengawal diri serta bersikap reaktif terhadap unsur persekitaran atau di motivasi oleh kehendak dalaman diri iaitu pembentukan kendiri. Teori ini juga berkait terhadap pengetahuan guru bahasa Melayu (PGBM) melalui pandangan terhadap usaha guru (human agency) untuk mencapai kejayaan dalam meningkatkan pencapaian dalam hidupnya. Ini jelas menunjukkan penguasaan kognitif yang baik mampu memberi kesan terhadap pencapaian kendiri seseorang individu dalam sebuah keluarga, masyarakat serta dalam sebuah organisasi.

Selain itu, dapat dilihat konsep kemahiran berdasarkan Model Peringkat Perkembangan Guru dalam meningkatkan pencapaian kendiri guru mampu memberi petunjuk terhadap perubahan konsep kendiri yang dimiliki oleh seseorang. Berpandukan model ini tahap perkembangan guru dilihat berubah dari satu tahap kepada satu tahap yang lain sehingga mencapai tahap tertinggi iaitu tahap yang membolehkan guru tersebut dianggap sebagai pakar dan berjaya meningkatkan pencapaian diri iaitu pencapaian dalam konsep kendiri. Dalam kajian Lunenburg dan Ornstein (2011) menyenaraikan lima tahap perkembangan guru sehingga melalui konsep guru pakar (expert's teacher) dalam meningkatkan pencapaian kendiri dalam hidup mereka sekali gus meningkatkan penguasaan konsep kendiri yang baik. Ini turut disokong oleh kajian Syahrul et al. (2019) menunjukkan tahap-tahap dalam perkembangan kendiri seseorang memerlukan penguasaan sikap dan pengetahuan dalam meningkatkan pencapaian konsep kendiri. Kajian mereka juga menunjukkan kendiri seseorang dipengaruhi oleh 
kefahaman seseorang individu dalam meningkatkan pencapaian diri yang berorientasikan konsep kendiri yang baik.

\section{Kerangka Konseptual Kajian}

Dalam kajian Ghazali dan Sufean (2016) menunjukkan kerangka konseptual adalah satu perhubungan yang dijadikan asas panduan dalam proses penyelidikan antara variabel dalam komponen-komponen penyelidikan yang dilakukan. Justeru dalam kajian kerangka konseptual kajian mengikut hubungan berganda iaitu dua pemboleh ubah bebas dan satu pemboleh ubah bersandar.

Rajah 1: Kerangka Konseptual Kajian Hubungan Pencapaian Kendiri Guru

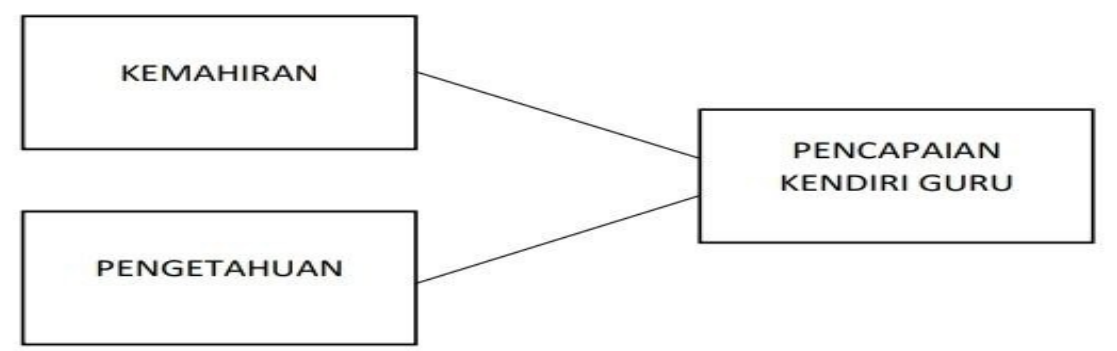

Hubungan pengetahuan dan kemahiran yang menjurus kepada pemboleh ubah bersandar iaitu pencapaian kendiri menjelaskan hubungan antara kedua-dua pemboleh ubah bebas dengan satu pemboleh ubah bersandar kajian. Kerangka konsep ini dapat menerangkan ujian statistik yang bersesuaian bagi menentukan hubungan setiap pemboleh ubah kajian yang dicadangkan melalui ujian korelasi.

\section{Pengetahuan}

Dalam kajian Nor Ashikin (2006) menunjukkan kekurangan dalam pengetahuan melibatkan kekurangan dalam perkongsian ilmu dan ketiadaan perbincangan tentang pengajaran dan pembelajaran dalam melakukan kerja-kerja yang diamanahkan yang dapat menyebabkan guru bertindak bersendirian seterusnya tidak dapat mengembangkan kemahiran mereka dan sekali gus menjejaskan prestasi pencapaian kerja di sekolah. Justeru ini akan mengakibatkan guru-guru cenderung untuk bekerja secara bersendirian dan tidak mengamalkan budaya perkongsian pengalaman dan bahan pengajaran dengan rakan sekerja mereka seperti apa yang sepatutnya seseorang guru tersebut lakukan sekiranya seseorang guru mempunyai kendiri positif ketika bekerja. Justeru, kepentingan penguasaan konsep kendiri dapat memberi panduan kepada guru-guru dalam melakukan kerja secara berkumpulan (Team Work) ketika menjalankan tugas sebagai pendidik sekaligus meningkatkan pencapaian kendiri yang baik.

\section{Kemahiran}

Kemahiran yang dimiliki oleh guru Bahasa Melayu dalam abad ke-21 merupakan keperluan yang melibatkan keupayaan, yang mana guru perlu peka tentang pelbagai kemungkinan yang akan berlaku dalam meningkatkan pencapaian kendiri di sekolah, yang memerlukan kepakaran individu seperti bekerja dengan mengadaptasi idea-idea di sekolah, perhubungan dengan rakan kerja di sekolah atau sistem yang wujud di sekolah. Ini kerana dalam kajian Soulé dan Warrick (2015) menunjukkan tahap pendidikan, dari peringkat rendah hingga peringkat kolej atau universiti, yang menggabungkan beberapa elemen seperti idea, hubungan rakan sekerja serta sistem sosial di sekolah yang berkait dengan pendidikan mesti berubah daripada pendidikan berasaskan disiplin tertentu kepada penyediaan modal insan yang berkemahiran abad ke-21 yang bersifat global, adaptasi teknologi dan maklumat. 


\section{Metod Kajian}

Kajian ini menghuraikan mengenai metodologi kajian dan diikuti dengan penerangan yang berkaitan dengan konsep kajian, teori, alat ukur kajian serta populasi dalam penyelidikan ini. Kajian tinjauan ini bertujuan untuk mengenal pasti sama ada terdapat hubungan antara pengetahuan dan kemahiran terhadap pencapaian kendiri guru Bahasa Melayu di Sabah. Dalam kajian ini, reka bentuk menggunakan pendekatan kuantitatif dan kaedah tinjauan yang bersesuaian dengan objektif, saiz populasi dan sampel kajian serta kedudukan geografi kajian. Menurut Gazali dan Sufean (2016) penyelidikan kuantitatif merujuk kepada kajian yang mana dapatan dihasilkan dengan menggunakan analisis statistik dalam bentuk angka. Selain itu, penggunaan kaedah soal selidik adalah kerana kesesuaian kaedah ini digunakan untuk penggunaan efektif dalam masa kajian dijalankan (Birmingham \& Wilkinson, 2003) dan kesan kajian, selain responden kajian (Sabitha, 2009). Menurut Ahmad Mahzan (1995) kaedah yang seragam yang dibuat memudahkan penyelidik menganalisis data dengan baik.

\section{Hasil Kajian}

Hipotesis kajian $\mathrm{HO} 1$ dan $\mathrm{HO} 2$ adalah untuk menguji sama ada wujud hubungan signifikan antara tahap Pengetahuan dan tahap Kemahiran dengan Pencapaian Kendiri guru Bahasa Melayu di negeri Sabah. Hipotesis nol yang akan diuji dalam kajian ini dinyatakan seperti berikut:

Ho1: Tidak terdapat hubungan yang signifikan antara pengetahuan guru dengan pencapaian kendiri guru bahasa Melayu Sekolah Kebangsaan di Sabah.

Ho2: Tidak terdapat hubungan yang signifikan antara kemahiran guru dengan pencapaian kendiri guru bahasa Melayu Sekolah Kebangsaan di Sabah.

Jadual 1 menunjukkan terdapat hubungan yang signifikan antara Pengetahuan dengan pencapaian kendiri guru bahasa Melayu di negeri Sabah $(r=0.739$, $\mathrm{p}<0.01)$. Justeru, hubungan antara kedua-duanya adalah sangat kuat. Maka HO1 yang menyatakan tidak terdapat hubungan yang signifikan antara pengetahuan dengan pencapaian kendiri guru bahasa Melayu di Sabah adalah ditolak.

Jadual 1: Hubungan Antara Pengetahuan dengan Pencapaian Kendiri Guru Bahasa Melayu

\begin{tabular}{llll}
\hline & & Pengetahuan & $\begin{array}{c}\text { Pencapaian } \\
\text { Kendiri }\end{array}$ \\
\hline \multirow{3}{*}{ Pengetahuan } & Pearson Correlation & 1 & $.739^{* *}$ \\
& Sig. (2-tailed) & & .000 \\
& $\mathrm{~N}$ & 380 & 380 \\
\hline \multirow{3}{*}{ Pencapaian Kendiri } & Pearson Correlation & $.739^{* *}$ & 1 \\
& Sig. (2-tailed) & .000 & 380 \\
\hline
\end{tabular}

**. Correlation is significant at the 0.01 level (2-tailed).

Jadual 1.2 menunjukkan terdapat hubungan yang signifikan antara Kemahiran dengan pencapaian kendiri guru bahasa Melayu di negeri Sabah $(r=0.750, p<0.01)$. Justeru, hubungan antara kedua-duanya adalah sangat kuat. Maka $\mathrm{HO} 2$ yang mengatakan tidak terdapat hubungan yang signifikan antara kemahiran dengan pencapaian kendiri guru bahasa Melayu adalah ditolak. 
Jadual 2: Hubungan Antara Kemahiran Dengan Pencapaian Kendiri Guru Bahasa Melayu

\begin{tabular}{llll}
\hline & & Tahap kemahiran & $\begin{array}{l}\text { Pencapaian } \\
\text { Kendiri }\end{array}$ \\
\hline \multirow{2}{*}{ Kemahiran } & Pearson Correlation & 1 & $.750^{* *}$ \\
& Sig. (2-tailed) & & .000 \\
& $\mathrm{~N}$ & 380 & 380 \\
\hline \multirow{2}{*}{ Pencapaian Kendiri } & Pearson Correlation & $.750^{* *}$ & 1 \\
& Sig. (2-tailed) & .000 & 380 \\
\hline
\end{tabular}

**. Correlation is significant at the 0.01 level (2-tailed).

\section{Perbincangan Kajian}

Berdasarkan hubungan antara pemboleh ubah yang terdiri daripada pengetahuan dan kemahiran guru bahasa Melayu dengan pencapaian kendiri menunjukkan terdapat hubungan yang kuat yang membawa maksud semakin meningkat pengetahuan dan kemahiran guru Bahasa Melayu, maka semakin terdapat peningkatan yang besar terhadap pencapaian konsep kendiri guru Bahasa Melayu di Sabah. Ini menunjukkan pengetahuan dan kemahiran merupakan pemboleh ubah yang sangat signifikan dalam meningkatkan pencapaian kendiri guru di Sabah.

Sementara pemboleh ubah bebas iaitu tahap kemahiran guru bahasa Melayu mempunyai hubungan yang sangat tinggi dengan pencapaian kendiri serta menunjukkan hubungan yang kuat. Dengan adanya hubungan yang kuat dengan tahap pengetahuan dan tahap kemahiran guru bahasa Melayu akan memberi impak yang positif terhadap kecemerlangan peningkatan pencapaian akademik seperti yang turut diperkatakan oleh Ghani et al. (2017) bahawa faktor kepakaran guru menguasai ilmu dan menepati perkembangan dalam menguasai kemahiran adalah faktor penting dalam menjamin kejayaan dan kecemerlangan sekolah dengan menitikberatkan apek pencapaian yang sebenar dalam diri guru itu iaitu pencapaian kendiri.

\section{Kesimpulan}

Pencapaian kendiri di sekolah dalam dunia pendidikan sangat penting dalam melahirkan guru Bahasa Melayu yang memiliki sikap yang unggul yang dapat menguasai pengetahuan dan kemahiran dalam setiap aspek tugas dan amanah yang diberikan terutama dalam meningkatkan pencapaian kendiri yang baik iaitu konsep kendiri yang selari dengan matlamat Falsafah Pendidikan Kebangsaan (FPK) negara dalam melahirkan guru-guru terpelajar dan berkemahiran menerusi pembentukan kendiri positif dalam diri seorang pendidik. Guru Bahasa Melayu perlu mempunyai kecemerlangan dalam setiap aspek sikap dan budaya kerja, agar dapat memberi kesan dalam meningkatkan pencapaian diri serta mempunyai semangat membimbing murid-murid melalui konsep kendiri positif yang diterapkan dalam kerja yang diamanahkan di sekolah. Justeru, seseorang guru yang terlatih dan berkemahiran akan cenderung memperbaiki pencapaian kendiri yang baik secara berterusan dan sering menunjukkan budaya kerja yang cemerlang dalam menjalankan tugas dan tanggungjawab sebagai guru Bahasa Melayu di sekolah.

\section{Rujukan}

Ahmad Mahzan Ayub. (1995). Kaedah Penyelidikan Sosioekonomi. Kuala Lumpur: Dewan Bahasa dan Pustaka. 
Aizat, K. (2016). Konsep 1Malaysia dan cabaran pelaksanaannya ke arah pemantapan perpaduan sebuah Negara-bangsa. Sosiohumanika, 4(1), 283-289.

Adriana Muhamad Akhir, Muhamad Suhaimi Taat, \& Syahrul Nizam Salam. (2020). Hubungan Sikap, Kesediaan Guru Dan Efikasi-Kendiri Guru Dengan Komuniti pembelajaran Profesional. International Journal of Education, Psychology and Counseling, 5(37), 221-231.

Adriana Muhamad Akhir, Muhamad Suhaimi Taat, \& Syahrul Nizam Salam (2020). Pengaruh Sikap, Kesediaan Guru Dan Efikasi-Kendiri Guru Terhadap Komuniti pembelajaran Profesional. International Journal of Modern Education, 2(7), 76-89

Bandura, A., \& Adams, N. E. (1977). Analysis of self-efficacy theory of behavioral change. Cognitive therapy and research, 1(4), 287-310.

Bandura, A. (1997). Social learning theory. Englewood Cliffs, NJ: Prentice Hall

Birmingham, P., \& Wilkinson, D. (2003). Using research instruments: A guide for researchers. Routledge.

Gazali \& Sufean (2016). Metodologi penyelidikan dalam pendidikan: Amalan dan analisis kajian. Penerbit Universiti Malaya.

Ghani, M. F. A., \& Crow, G. M. (2017). Amalan komuniti pembelajaran profesional: Perspektif pemimpin sekolah cemerlang negara maju. JuKu: Jurnal Kurikulum \& Pengajaran Asia Pasifik, 1(3), 10-27.

Klapp, A. (2018). Does academic and social self-concept and motivation explain the effect of grading on students' achievement?. European Journal of Psychology of Education, 33(2), 355-376.

Lunenburg, F. C. \& Ornstein, A. C. (2008). Educational administration: Concepts and practices. Fifth ed. Belmont, CA: Thomson Books/Cole.

Mohd Hussin Musa, Christina Andin \& Syahrul Nizam Salam. (2020). Kesahan Dan Kebolehpercayaan Instrumen Pentaksiran Kemahiran Insaniah Murid (IPKIM) Mata Pelajaran Rekacipta. International Journal of Education, Psychology and Counseling, 5(37), 96-107.

Norin Farizah Mohd Nuin, Abdul Said Ambotang, \& Syahrul Nizam Salam. (2020) Pengaruh motivasi dan kompetensi terhadap perubahan pengurusan data murid di Sabah. International Journal of Education, Psychology and Counselling, 5(34), 116-125.

Syahrul Nizam Salam, Abdul Said Ambotang, \& Ghazali Hassan Sulaiman. (2018). Pengaruh Faktor Penyumbang Terhadap Kendiri Pelajar Ekonomi Tingkatan Enam Di Sabah. Jurnal Penyelidikan Akademik, Institut Pendidikan Guru Malaysia, Kementerian Pendidikan Malaysia, 3(34), 34-51

Syahrul Nizam Salam, Abdul Said Ambotang, Ghazali Hassan Sulaiman. (2019). Hubungan Sikap Terhadap Ekonomi Dan Kefahaman Konsep Ekonomi Dengan Kendiri Pelajar Ekonomi. Jurnal Kurikulum Kementerian Pendidikan Malaysia, 4(34), 16-29

Soulé, H., \& Warrick, T. (2015). Defining 21st century readiness for all students: What we know and how to get there. Psychology of Aesthetics, Creativity, and the Arts, 9(2), 178.

van Rooij, E. C. M., Fokkens-Bruinsma, M., \& Goedhart, M. (2019). Preparing science undergraduates for a teaching career: Sources of their teacher self-efficacy. The Teacher Educator, 54(3), 270-294.

van Rooij, E. C., Jansen, E. P., \& van de Grift, W. J. (2017). Factors that contribute to secondary school students' self-efficacy in being a successful university student. Research in PostCompulsory Education, 22(4), 535-555. 